\title{
Experimental Techniques: Developments, Applications and Tutorials in Experimental Mechanics Techniques
}

\author{
P. Reynolds ${ }^{1}$
}

Published online: 21 December 2015

(C) The Society for Experimental Mechanics, Inc 2015

We are excited to re-introduce Experimental Techniques (ET) as the flagship applications journal of the Society for Experimental Mechanics (SEM) in association with our new publisher Springer. We wish to invite you to submit your best work on developments, applications and tutorials in the field of experimental mechanics to the journal at www. editorialmanager.com/exte and to help in getting the word out to your colleagues at http://springer.com/40799.

\section{Genesis of Experimental Techniques - from Newsletter to Magazine to peer reviewed Journal (1970s-now)}

Experimental Techniques (ET) started life as a Society for Experimental Mechanics (SEM) newsletter to its members back in the mid-70s and evolved, due in large part to the patience, tenacity, and passion of SEM's first female President, Susan K. Foss, into SEM's first member publication. Susan actively recruited a number of associate editors morphing the newsletter into a Society publication containing short "how to" articles for the practicing engineer. This happened in the early 1980s as it continued its evolution into Experimental Techniques, the Magazine, which contained how-to articles, along with segments for news of the Society and advertisements from our meeting exhibitors. The ET magazine format lasted until 1990, when the newsletter portion of the publication changed its name to ETcetera.

P. Reynolds

p.reynolds@exeter.ac.uk

1 College of Engineering, Mathematics and Physical Sciences, University of Exeter, North Park Road, Exeter EX4 4QF, UK
In 1995, the format added a section up front called "President's Corner" and maintained the Etcetera news plus the short how-to articles that were now up to about eight per issue. By the end of 1997, the Executive Director and Publisher of the Society added a column in addition to the existing elements of the publication. In essence, it was still a magazine with a newsletter and a compliment of technical articles that had evolved from the "how to" arena to the truly "Applications" arena. With this, the content of the publication evolved to become longer, with applications related articles that specifically targeted the practicing engineer by adding our members' work in the area of experimental mechanics. Additionally, in 1998 the publication launched a series called Back-to-Basics focusing on short modal analysis articles, representing the foundation of the conference that SEM manages at the beginning of every year called IMAC (formerly the "International Modal Analysis Conference"). The series was authored by Professor Peter Avitabile from the University of Massachusetts at Lowell.

It was clear that the readership were very interested in this new series and in supporting the evolution, content and growth of ET. In 2002, a further Back-to-Basics series was added, focusing on optical methods and authored by Professor Gary Cloud from Michigan State University. The two departments were typically the most requested articles in the publication. They were very instructional and very easy to adapt to the classroom. The momentum from the membership to keep growing and expanding ET stayed strong as the readership and interest continued to increase.

The Society, during this entire time, was its own publisher and was able to grow the publication only so far. Conversations, proposals and serious talk of hiring a publisher to take on the publication came to fruition in 2005 when SEM signed a contract with Blackwell Publishing (now Wiley) to help ET grow into what is has become today. The first issue 
with the new publisher showed new cover art and the title Experimental Techniques with the tagline Developments, Applications and Tutorials in Experimental Mechanics Techniques. In 2011, ET completed another major step into the Journal arena with its transformation into a peer reviewed Applications Journal. The newsletter portion was removed to become its own stand-alone newsletter called, Experimentally Speaking, and the two Back-to-Basics series were wrapped up in order to become a downloadable archived series on the SEM website. We continued the Feature Series to keep our finger on the pulse of emerging areas. Going forward, topics covered by the Feature Series will change with the ever changing shifts in the emerging experimental mechanics application arena.

Now, with the transition to our new publisher Springer, Experimental Techniques can accelerate its growth across global markets and continue to grow its Impact Factor, citations, submissions and downloads. The journal will continue to provide for its authors a perfect platform for publishing in the experimental mechanics applications arena and offer many new options for expanding readership in the e-space and traditional publication space.

\section{Journal Scope}

Our aims and scope for the Journal are consistent with the mission and goals of SEM and the publication that we have evolved into. Specifically:

Experimental Techniques is a bimonthly interdisciplinary publication of the Society for Experimental Mechanics focusing on the development, application and tutorial of experimental mechanics techniques.

The purpose of Experimental Techniques is to promote pedagogical, technical and practical advancements in experimental mechanics while supporting the Society's mission and commitment to interdisciplinary application, research and development, education, and active promotion of experimental methods to:

- Increase the knowledge of physical phenomena

- Further the understanding of the behavior of materials, structures, and systems

- Provide the necessary physical observations necessary to improve and assess new analytical and computational approaches.

Experimental Techniques accepts articles that focus on practical applications of experimental mechanics and innovative techniques used to create engineering solutions. This includes, but is not limited to, experimental observations and methods, analytical or computational methods linked to observations of physical phenomena, and non-deterministic analysis of experimental observations. The Editors encourage the submission of articles that describe approaches to education and training in experimental mechanics and structural dynamics.

\section{Moving Forward}

Experimental Techniques has always represented a wonderful means to communicate and share, often through a pedagogical style, the applications work of our members to our members. With the evolution of the publication over time, we have opened the ability to publish in the journal to all interested experimental mechanicians working specifically on applications areas and those developing novel experimental and data analysis technologies.

The list of editors is shown at the opening of this article. Many of the editors and past Editors in Chief have been past SEM Presidents. This in itself represents the special place that Experimental Techniques has always held as a very important publication for the members.

I have been the Chair of SEM's Applications Committee over the past few years and have had the privilege of being able to observe and assess the thousands of presentations and papers presented at the two major conferences held each year by SEM. The number of applications papers is growing. I hope that you find that this journal is the most appropriate venue to publish your Experimental Techniques and applications work. Also, if you have an idea for a new Feature Series, then please contact me directly to share your thoughts and ideas.

Please enjoy this inaugural issue of Experimental Techniques with Springer as our new publisher. This first issue, Volume 40, Issue 1, 2016, is larger than typical in order to release the backlog that has built up due to the overwhelming popularity of the journal. We hope that this will send you, the readership and potential authors, the signal that we are being responsive and welcome your articles to the journal with a promise of far faster publication time than you may have previously experienced.

We thank you for your interest and sincerely invite you to submit your state-of-the-art work to Experimental Techniques. We welcome suggestions for improvements to the journal as it grows. With the strength of the ever-growing experimental mechanics applications community, we are confident that Experimental Techniques will continue to be a great success with your support and contributions.

Professor Paul Reynolds

Editor in Chief 